\title{
MÉTODOS MÓVEIS NO CONTEXTO DO PARADIGMA DAS NOVAS MOBILIDADES
}

Manolita Correia Lima, Claudia Cristiane dos Santos Silva, Danilo Martins Torini ${ }^{1}$

Escola Superior de Propaganda e Marketing - ESPM, São Paulo, Brasil

\section{DETALHES DO ARTIGO}

Histórico do Artigo:

Artigo Convidado

Disponível online: 01 de abril de 2019

Sistema de revisão "Double blind review"

Editor Científico

Ilan Avrichir

Palavras-chave

Novas Mobilidades

Métodos Móveis

Mobilidade Acadêmica Internacional

\begin{abstract}
RESUMO
Refletir-se-á sobre a proposta de renovação dos recursos metodológicos requeridos pela investigação de temas relacionados às "novas mobilidades". A literatura dedicada à compreensão dos impactos decorrentes das referidas mobilidades tem argumentado a necessidade de se repensar os recursos metodológicos explorados e a importância de formular alternativas metodológicas àquelas recorrentemente exploradas. Levando em conta que os autores deste texto integram um grupo de pesquisa dedicado à investigação da mobilidade acadêmica internacional e a prática da pesquisa apontar para as limitações dos recursos metodológicos tradicionalmente explorados, resolveram consolidar as contribuições que a literatura internacional tem oferecido nesse campo e socializar com os interessados. O texto será dividido em duas partes: enquanto a primeira aprofunda o paradigma das novas mobilidades formulado pelos pesquisadores do Centre for Mobilities Research (Lancaster University); a segunda discute o que os estudiosos do campo vêm nomeando de "métodos móveis". Levando em consideração que as possibilidades de uso dos métodos móveis são tão amplas e diversificadas quanto o campo aberto pelo "paradigma das novas mobilidades", o texto será ilustrado com exemplos extraídos de pesquisas sobre a mobilidade acadêmica internacional, com foco na discussão de técnicas que fazem uso intensivo de tecnologia da informação e de dispositivos móveis, sem desconsiderar as questões éticas.
\end{abstract}

(C) 2018 Internext | ESPM. Todos os direitos reservados!

\section{INTRODUÇÃO}

Com o ensaio acadêmico objetiva-se refletir sobre a proposta de renovação dos recursos metodológicos requeridos pela investigação de temas relacionados às "novas mobilidades". A literatura dedicada à compreensão dos fenômenos decorrentes das referidas mobilidades tem argumentado não apenas a necessidade de se repensar os recursos metodológicos explorados pelos pesquisadores, mas também a necessidade de propor alternativas metodológicas àquelas recorrentemente exploradas na maioria das pesquisas publicadas (Sheller \& Urry, 2005). Levando em conta que os autores integram um grupo de pesquisa que tem se dedicando à investigação da mobilidade acadêmica internacional e que a prática da pesquisa aponta para as limitações dos recursos metodológicos tradicionalmente explorados, resolveram consolidar as contribuições que a literatura internacional tem oferecido nesse campo e socializar com os interessados.

Frente ao desafio antes descrito, os conteúdos do capítulo estão divididos em duas partes: enquanto a primeira situa o paradigma das novas mobilidades, proposto por John Urry (2005; 2007) e equipe (Centre for Mobilities Research - CeMoRe, vinculado à Lancaster University); a segunda discute o que os estudiosos do campo vem nomeando de métodos móveis. Chama-se atenção para o fato de as possibilidades de uso dos métodos móveis serem tão amplas e diversificadas quanto o campo aberto pelo paradigma das novas mobilidades. No entanto, em virtude da linha de pesquisa dos autores, há preocupação de ilustrar o texto com exemplos 
extraídos de pesquisas sobre a mobilidade acadêmica internacional.

\section{A Gênese das Novas Mobilidades}

O capitalismo industrial fomentou a produção de massa materializada na fabricação de bens estandardizados e dependentes de rígida organização do trabalho. Esse ambiente propiciou a emergência de teorias orientadas para a organização científica do trabalho e do estabelecimento de práticas capazes de regular o tempo e os movimentos, cujo êxito dependia da sedentarização dos trabalhadores. Na busca da fidelidade à empresa, da disciplina e dedicação ao trabalho, da redução de custos e do aumento da produtividade, os empregadores investiram na construção de vilas, bairros e até cidades operárias, alterando sobremaneira a paisagem urbana. Nesse contexto, a sociedade disciplinada na qual os comportamentos são regidos pelo confinamento dos indivíduos em distintos lugares, a exemplo das escolas, universidades, hospitais, prisões e vilas operárias, correspondem ao "modo de regulação social fordista" (Fraser, 2003 apud Rousseau, 2008, p.190). Contudo, em meio às crises deflagradas na década de 1970, o regime de acumulação flexível, estreitamente vinculado à mobilidade do capital, ganha força e pressupõe rearranjos na organização da força de trabalho, implicando redução de postos de trabalho; multiplicação dos empregos temporários, flexíveis e de meio período; além da valorização da mobilidade do capital humano (Ouziel, 2004). Assim, desde o período da transição da modernidade para a pósmodernidade, pessoas, organizações, objetos e capitais estão se desprendendo da fixidez, e deslocando-se cada vez mais.

O paradigma das novas mobilidades, assim nomeado e proposto por John Urry, é associado ao incremento das tecnologias de transporte e de comunicação, com a desmaterialização das conexões resultante do surgimento de novos aparelhos tecnológicos tais como telefones celulares, ipods, laptops, tablets, smartphones, drones, smartwatchse demais dispositivos vestíveis (wearables), entre outros (Urry, 2007). A consequência do aumento da convergência entre transportes e comunicação não é modesta na medida em que impacta sobre a redefinição da relação espaço-tempo, implicando em novas combinações de presença e ausência na sociedade. Levando em conta esse contexto, Sheller e Urry (2005) asseguram que todos os lugares estão interligados em redes de conexões que ultrapassam qualquer tipo de fronteira.

\section{As Novas Mobilidades como Expressão de Status e Poder}

As mobilidades corpórea e virtual podem ser vistas como fonte de status e de poder. Não é sem razão de ser que quanto maior for o acesso a recursos tecnológicos tais como smartphones, laptops, tablets, maior será o networking dos indivíduos (Sheller \& Urry, 2005). Por isso mesmo, enquanto empresários, executivos, diplomatas, cientistas, professores, estudantes, artistas e esportistas ganham cidadania global, encarnam a descrição do turista, proposta por Bauman (1999, p.101); os refugiados se convertem no que o autor nomeia de refugo humano. Cabe destacar que em uma sociedade de consumo, a mobilidade figura como um bem de consumo; assim sendo, dependendo da classe social que o indivíduo está inserido, a mobilidade corpórea pode assumir distintos significados (Bauman, 1999). É nessa trilha que o conceito de vagabundo, formulado pelo autor (1999), diverge do sentido impresso ao termo por Rousseau (2008), e pode ajudar na argumentação. Para Bauman (1999, p.104), vagabundo representa uma categoria social inútil em virtude de sua condição de consumidor frustrado, razão pela qual ele é indesejável e o discurso em defesa da adoção de leis que dificultam, quando não impedem, a mobilidade corpórea desse grupo social, ganha crescente número de adeptos, institucionalizando uma espécie de apartheid migratoire (Terrier, 2010, p.59), agravado pela criminalização da miséria (Rousseau, 2008, p.197). Logo, em uma sociedade de consumo, a associação entre o capital de mobilidade e a liberdade para escolher onde estar, é que estratifica seus membros (Bauman, 1999, p.94). Isso equivale a afirmar que apesar da revolução tecnológica, seja no âmbito do transporte ou da informação, a mobilidade corpórea tem o poder de reforçar as desigualdades sociais (Bauman, 2017, 2008, 1999; Santos, 2003).

Sobre a desigualdade de direito à mobilidade, Withol de Wenden (2009 apud Terrier, 2010, p.56) denuncia que "em um mundo onde tudo flui mais livremente, exceto os homens, a democratização das fronteiras ainda não é uma realidade". Indício disso reside no fato de que, apesar de os Estados Unidose do Reino Unido serem os países que mais atraem as pessoas em mobilidade internacional, são justamente os que mais formulam políticas restritivas à imigração. Isso ajuda a se entender porque Le 
Breton (2005) e Sheller (2011) enfatizam a importância de as pesquisas derivadas do novo paradigma da mobilidade aprofundarem questões relativas à exclusão e ao direito à mobilidade.

Compreensivelmente, a mobilidade internacional estudantil é desejada por todos, porque confere aos países acolhedores a afirmação da superioridade acadêmica e tudo que isso pode significar em termos políticos, econômicos e culturais. Tanto é que em documento oficial do Governo francês, a deputada francesa Aurélie Filippetti (2007, p.17-18) faz questão de evidenciar as vantagens diretas da política de atração de estudantes internacionais: a) colabora para a instalação de uma diplomacia influente; b) contribui para a formação de uma espécie de viveiro de cérebros; c) ajuda a extrair da atratividade educacional benefícios econômicos; d) contribui para, por determinado tempo, desfrutar-se da mão de obra qualificada que ajudou a formar; e) colabora para os governantes lutarem contra a fuga de cérebros; f) e ainda ajuda o governo a administrar a imigração não controlada (clandestine).

Assim sendo, os países com elevada capacidade de atração de estudantes internacionais reafirmam que as fronteiras estão permanentemente abertas para as elites políticas, econômicas e intelectuais. Porém, o mesmo não se pode afirmar em relação aos trabalhadores pouco qualificados, oriundos de países periféricos, sem qualquer relevância econômica e peso político. Por tudo isso, a mobilidade tornou-se "o fator de estratificação mais poderoso e mais cobiçado, a matéria de que são feitas e refeitas, diariamente, as novas hierarquias sociais, políticas, econômicas e culturais em escala cada vez mais mundial" (Bauman, 1999, p.16). Afinal, como constata Wagner (1998, p.11) em sua pesquisa sobre as novas elites da mundialização, a mobilidade das pessoas tende a acompanhar a dinâmica dos investimentos em escala planetária (Wagner, 1998, p.11).

\section{As Novas mobilidades - Um Fenômeno que Ganha Múltiplas Dimensões}

A mobilidade corpórea ainda pode assumir uma dimensão coercitiva e desencadear sofrimento, constrangimentos e privações, como no caso de pessoas que fogem de seus países em virtude de catástrofes naturais, conflitos armados, perseguição política e violação dos direitos humanos ou quando são vítimas do crime de tráfego de pessoas para fins trabalho forçado, casamento forçado ou exploração sexual, tráfico de drogas, extração de órgãos ou tecidos, entre ouros (Sheller \& Urry, 2005).

O drama enfrentado pelos refugiados vem sendo amplamente divulgado, não são poucas as imagens que circulam nas mídias sociais, expondo cenas dramáticas que de tão recorrentes parecem não comover mais os "espectadores", contribuindo para gerar o que Bauman $(2017$, p. 8) nomeia de "fadiga da tragédia dos refugiados". Mas elas escancaram as consequências visíveis da combinação entre a brutalidade das guerras (guerra civil na Líbia, na República Democrática do Congo, na Síria por exemplo), dos conflitos armados (no Afeganistão, Iraque, lêmen, Egito, Nigéria, Ucrânia e Rússia, por exemplo) e das catástrofes naturais (terremotos, furacões, ciclones, tufões, tornados, incêndios florestais). Todos esses eventos têm em comum o fato de expulsar elevados contingentes humanos de seu país de origem. Mas recorrentemente os refugiados acabam "não encontrando um lugar no mundo onde possam existir dignamente [...] não possuem um status político que lhes possibilite ser tratados pelos demais como semelhantes" (Winckler, 2001, p.121).

Observa-se, então, que a dimensão transversal da mobilidade espacial passa a ser considerada na medida em que ela atinge distintos aspectos da existência humana: físico e mental, individual e social; local, regional e global etc. Em virtude dessa compreensão, os pesquisadores do campo estabelecem clara relação entre mobilidade espacial e origem social (Terrier, 2010). Asseguram que as classes mais favorecidas controlam a gestão da mobilidade uma vez que o espaço traduz simbolismos explícitos ou clandestinos próprios do cotidiano, do particular, e do vivido. Mas, sobretudo, transmite mensagens hegemônicas de explicitação do poder e da dominação (Lefebvre, 2000). Isso equivale a afirmar que o controle do espaço permite o controle da mobilidade do corpo (Rousseau, 2008), justificando a flagrante assimetria encontrada não apenas no plano da geografia dos fluxos de mobilidade corpórea (Terrier, 2010).

Bourdin (2002) entende as mobilidades como expressões de mudança de posição que podem ocorrer no espaço real ou virtual, consequentemente, o fenômeno pode se manifestar de distintas formas. A mobilidade física corresponde aos deslocamentos e as mudanças de ambiente necessários à vida social, incluindo também 
deslocamentos forçados (Urry, 2007, p.7). A mobilidade social, por sua vez, refere-se à mudança de profissão ou de empresa, de nível socioeconômico ou de meio social; a mobilidade axiológica traduz mudanças no sistema de valores; a mobilidade cultural expressa mudanças na maneira de se comportar; a mobilidade afetiva ocorre quando os investimentos afetivos se deslocam na direção de outras pessoas ou de outros objetos; e a mobilidade cognitiva, traduz mudanças do referencial cognitivo resultante da compreensão do universo formado por conhecimentos estranhos à determinada área (Bourdin, 2007). Atendo-se a mobilidade espacial, Le Breton (2005) reconhece a existência de três categorias: a modalidade física corresponde aos deslocamentos dos corpos no espaço, sejam eles espontâneos ou não, cotidianos ou esporádicos, de curto, médio ou longo prazo; a virtual resulta do uso intensivo das tecnologias digitais; e as mobilidades mentais, por sua vez, revelam mudanças que se processam no universo das representações sociais. A preocupação de caracterizar as mobilidades também está presente nos textos de Cresswell (2006). Para o geógrafo, a produção da mobilidade assume um caráter bifacial na medida em que o fenômeno combina uma dimensão corporal e outra social. Quando a mobilidade é entendida como fenômeno social inevitavelmente envolve estruturas, meios, culturas e significados. Assim sendo, na trilha do que já foi argumentado por Lefebvre (2000), Cresswell (2006) reitera que a sua compreensão não pode ser reduzida a mero deslocamento. Sobre isso, Veschambre (et al 2004 apud Terrier, 2010, p.48) é categórico ao afirmar que "a problemática das mobilidades ultrapassa a questão dos deslocamentos uma vez que busca compreender as composições sociais e espaciais que tais deslocamentos supõem e geram". A compreensão do fenômeno por este prisma reforça a necessidade de se formular metodologias de pesquisa móveis (Urry, 2007).

\section{As Novas Mobilidades como o Centro da Vida Social}

Sensíveis à rapidez e intensidade com que as mobilidades têm se manifestado, em obra colegiada, reveladoramente intitulada Olhares sobre os mundos hypermóveis - mitos e realidades (Regards sur les mondes hypermobiles - mythes et réalités), os organizadores fazem uso de todos os termos no plural, sugerindo a relevância de se investir em múltiplos acerca de um mundo marcado pela (hiper)mobilidade. Na apresentação da obra, os autores e organizadores (Dervin e Ljalikova, 2008, pp.9-10) justificam que o uso do prefixo "'hiper' destaca tanto a pluralidade das formas de mobilidade que afetam as sociedades do Século 21, quanto a intensidade com que essas mobilidades parecem se impor aos indivíduos contemporâneos". Constatação que explica a importância de o tema ser investigado numa perspectiva pós-disciplinar, seguramente mais exigente em virtude do reconhecimento da complexidade do fenômeno.

$\mathrm{Na}$ contemporaneidade, da gripe aviária aos acidentes de trem; da expansão de aeroportos ao congestionamento aéreo e ao aquecimento global; das manifestações políticas ao terrorismo global em rede; sem esquecer a gestão de situações de emergência decorrentes de tsunamis, terremotos, furacões ou erupções vulcânicas, a mobilidade situase no centro destes eventos. Assim sendo, tanto as organizações públicas, quanto as privadas e sem fins lucrativos estão progressivamente procurando compreender, monitorar, gerenciar e transformar aspectos destas múltiplas mobilidades, e das novas imobilidades, exclusões sociais e ameaças de segurança que podem de uma forma ou de outra, estar associada a elas (Hannan, et al, 2006). Além de entender os meandros intrinsecos às mobilidades, faz-se igualmente necessário investigar as imobilidades refletidas em lugares onde o movimento está temporariamente estagnado ou atenuado, fronteiras, aeroportos, rodovias, hotéis, motéis, hospitais, centros de detenção, campos de refugiados etc. (Sheller, 2011). Ressalta-se que a pesquisa no contexto deste paradigma, em seu sentido mais amplo, leva em conta não apenas o movimento físico, mas também o movimento potencial, o movimento bloqueado e a imobilização (Urry, 2007). Segundo Cresswel (2010), compreender estas questões em conjunto acrescenta mais do que a soma das partes. Para ele, a pesquisa das mobilidades conjectura sobre uma variedade de elementos que se movem, incluindo os seres humanos, ideias e objetos. O autor se interessa particularmente em compreender como essas coisas se movem por caminhos que se interligam e como são capazes de permitir ou impedir que outras se movam. No contexto das novas mobilidades, Urry (2007) reconhece a existência de cinco dimensões, sem desconsiderar suas inevitáveis inter-relações (Quadro 1): viagem corpórea, movimento físico dos objetos, viagem imaginativa, viagem comunicativas e viagem virtual. 


\begin{tabular}{|c|l|}
\hline \multirow{2}{*}{$\begin{array}{c}\text { Dimensões } \\
\text { do Novo }\end{array}$} & $\begin{array}{l}\text { Viagem corpórea de pessoas que se deslocam por motivos que transitam entre trabalho, lazer, } \\
\text { vida familiar, prazer, estudo, migração e fuga. Estas mobilidades podem envolver desde os } \\
\text { deslocamentos diários, até deslocamentos únicos (uma espécie de exílio) }\end{array}$ \\
\cline { 2 - 2 } $\begin{array}{c}\text { Paradigma } \\
\text { da Mobilidade }\end{array}$ & $\begin{array}{l}\text { Movimento físico de objetos para produtores, consumidores e varejistas, o envio e recebimento } \\
\text { de presentes e lembranças, bem como a montagem e (re)configuração das pessoas, objetos e } \\
\text { espaços como parte de habitação e lugar de decisões }\end{array}$ \\
\cline { 2 - 3 } & $\begin{array}{l}\text { Viagem imaginativa realizada por meio de conversas, mas também de imagens de lugares e povos } \\
\text { referenciados e movendo-se através de impressão múltipla e mídia visual }\end{array}$ \\
\cline { 2 - 3 } & $\begin{array}{l}\text { Viagem comunicativa através do contato pessoa-a-pessoa via sistemas de mensagens, textos, } \\
\text { cartas, telégrafo, telefone, fax e móveis }\end{array}$ \\
\cline { 2 - 3 } & $\begin{array}{l}\text { Viagem virtual, muitas vezes em tempo real, permite a presença e ação à distância, transcender } \\
\text { a distância geográfica e social (por exemplo, transferência bancária via Internet ou participar de } \\
\text { uma reunião ou de uma conferência 'em' second life). }\end{array}$ \\
\hline
\end{tabular}

Quadro 1: Dimensões do Novo Paradigma da Mobilidade

Fonte: Urry (2007), adaptado pelos autores, 2018.

Ao observar este quadro, percebe-se a complexidade no que tange a realização do exercício de investigação do fenômeno, complexo por se. Observa-se que as múltiplas mobilidades se interseccionam em sistemas e evoluem no sentido de uma relação em que as dimensões se adaptam uma as outras, revelam uma trilha para análises na perspectiva do que Hayles (1999) propõe como póshumano. Até então, o ser-humano pensava e agia independente da perspectiva material, assim sendo, o humano era caracterizado por uma cognição desacoplada do mundo material (Büscher \& Urry, 2009), perspectiva impensável no âmbito do paradigma das novas mobilidades.

As transformações antes descritas impõem desafios metodológicos para aqueles que investigam objetos de estudo derivados das novas mobilidades. Captar os múltiplos aspectos envolvidos no fenômeno implica em lançar mão de recursos diferenciados no que tange as técnicas de coleta de dados. Assim sendo, na sequência serão abordadas questões que emergem no processo investigatório das novas mobilidades.

\section{O Paradigma das Novas Mobilidades}

A transversalidade das novas mobilidades justifica o espaço que o tema tem ocupado na academia, com a publicação de livros, revistas especializadas, defesa de teses (Garneau, 2006; Ballatore, 2007; Dervin, 2008; Terrier, 2010, entre outras), organização de reuniões acadêmicas consagradas à discussão do tema. Motiva, ainda, a criação de sites, páginas e comunidades nas mídias sociais, realização de levantamentos mundiais conduzidos pela Organização das Nações Unidas para a educação, a ciência e a cultura (UNESCO) e pela Organização para a Cooperação e Desenvolvimento Econômico (OCDE), entre outros.

A sistematização do campo está em construção particularmente com o trabalho realizado por pesquisadores europeus uma vez que nessa região, em período recente, a mobilidade internacional envolve todos os níveis de ensino, do maternal ao superior, do técnico ao científico, além do ambiente profissional (Zarate, 1999). Exemplos de acadêmicos dedicados à compreensão da mobilidade em suas distintas manifestações seriam o engenheiro civil, Georges Amar (2011; 2016); o cientista político, Max Rousseau (2008); o antropólogo, Marc Augé (2009); os geógrafos, John Adams (2000; 2001), Jacques Lévy (2008) e Tim Cresswell (2006); os sociólogos Alain Bourdin (2007), Éric Le Breton (2005) e John Urry (2005; 2007), entre muitos outros.

Em virtude da riqueza do universo empírico aberto pela criação de programas de incentivo à mobilidade acadêmica internacional, observa-se que nas duas últimas décadas, pesquisadores de distintas áreas de conhecimento dedicam-se à investigação dos múltiplos aspectos envolvidos com a mobilidade física de estudantes internacionais: Régis Machart e Fred Dervin (2014), Carolina Pinto (2013), Valérie Erlich (2012), Vincenzo Cicchelli (2012), Magali Ballatore (2010; 2007), Eugenie Terrier (2010), Fred Dervin e Michael Byram (2008), Fred Dervin e Aleksandra Ljalikova (2008), Dominique Ulma (2008); 
Ridha Ennafaa e Saeed Paivandi (2008), Fred Dervin e Eija Soumela-Salmi (2007); Sandrine Billaud (2007); Stéphanie Garneau (2006); Ana Maria F. Almeida et al. (2004), Elisabeth Murphy-Lejeune (2003), entre muitos outros. Apesar disso, Sheller e Urry (2005) afirmam que as Ciências Sociais ignoraram a importância do "movimento sistemático", seja no âmbito do trabalho, no universo da vida familiar, assim como no lazer e no prazer, na política e no protesto.

Em um momento marcado pelo desafio de compreender os impactos decorrentes das múltiplas mobilidades, Jonh Urry (2005) propõe as novas mobilidades como o tema central da Sociologia na medida em que assegura que contemporaneamente as mobilidades passam a ser o centro da vida social. Nas palavras do autor, "no coração da vida social e, portanto, deve ser central para a análise sociológica" (Urry, 2005, p.49). Frente ao exposto, Urry recomenda alterações estruturantes na Sociologia na medida em que argumenta a necessidade de alterações que ultrapassam o objeto de estudo da Sociologia porque envolve aspectos relacionados ao método e à natureza do questionamento acerca dos fenômenos sociais. Em linha de colisão com os clássicos da Sociologia - Emile Durkheim, Karl Maxe Max Weber -, Urry $(2005 ; 2007)$ argumenta que em vez de buscar compreender o estado estático, a estrutura e a ordem social, as novas regras do método sociológico consistiriam em desenvolver uma Sociologia orientada pelo movimento, empenhandose em compreender transversalmente a problemática das mobilidades. Consistiria ainda em investigar a extensão e os efeitos decorrentes desse fenômeno complexo e multifacetado; a maneira pela qual as classes sociais, o gênero, as etnias e as nações se constituem, levando em conta os modos como constroem, apropriam-se e praticam os espaços, como habitam e se movimentam nesses espaços, evitando reducionismos nos resultados das investigações realizadas. Proposição que ele nomeou paradigma das novas mobilidades. Nas palavras do autor (2007, p.18), "será argumentado que mobilidades não são apenas substancialmente diferentes, em que remedia a negligência e omissões dos vários tipos de movimentos de pessoas, ideias e assim por diante, mas é transformadora da Ciência Social, autorizando uma paisagem teórica e metodológica alternativa, como eu detalho (sic)" (Urry, 2007 p.18).
O empreendimento teórico-metodológico proposto por Urry não é modesto, particularmente quando ele explicita o interesse de formular um novo paradigma para a Sociologia. Em suas palavras, "eu procuro (sic) estabelecer e estabilizar uma nova intercessão ou pós-disciplinar paradigma das mobilidades". O autor está convencido de que pensar através da "lente' das mobilidades requer uma Ciência Social distinta, capaz de produzir diferentes teorias, métodos, questões e soluções (Urry, 2007 p. 18). Cabe lembrar que a estabilidade de um paradigma pressupõe a existência de condições teórico-metodológicas que orientem as investigações científicas, sem desconsiderar a capacidade de responder às questões geradas no âmbito do contexto (Kuhn, 1962). Levando em conta as novas e múltiplas mobilidades, os diversos olhares propostos por acadêmicos oriundos de distintos campos de conhecimento, a cautela e a modéstia são atitudes que merecem ser cultivadas. Curiosamente, ao se referir à produção acadêmica de Urry, particularmente ao livro intitulado Mobilities (2007), Mimi Sheller (2011, p.9), uma das pesquisadoras do CeMoRe, é categórica ao afirmar que a obra corresponde a um "guia definitivo" (sic) para o campo da pesquisa sobre mobilidades uma vez que o autor mapeou as áreas de pesquisa, formulou princípios gerais, sobretudo, apontou as implicações das novas mobilidades para as Ciências Sociais. Em seus termos, "um dos primeiros guias definitivos para o campo de investigação das mobilidades, por um de seus principais teóricos, introduzindo seus princípios centrais, áreas de investigação e implicações para as ciências sociais" (Sheller, 2011, p.9). De fato, no referido livro, o autor determina e orienta a direção que acredita ser a mais adequada às investigações sobre as novas mobilidades, a exemplo do extrato que segue:

Ele [o paradigma das novas mobilidades] permite que
o "mundo social" seja teorizado como uma grande
variedade de práticas econômicas, sociais e políticas,
infraestruturas e ideologias que envolvem todos,
implicam ou reduzem os vários tipos de movimentos
de pessoas, ideias, informações ou objetos. E assim,
fazendo este paradigma trazer à tona as teorias,
métodos e exemplos de pesquisas que têm sido
maioritariamente subterrânea, vista de fora. Então, eu
uso o termo mobilidades para me referir ao projeto
mais amplo de criação de uma Ciência Social orientada
pelo movimento (Urry, 2007, p.18).

Levando em conta que o paradigma das novas mobilidades pressupõe mudanças estruturais no 
âmbito das Ciências Sociais, que isso coloca em dúvida a leitura monodisciplinar dos fenômenos investigados, na direção do que tem sido nomeado de post-disciplinary, e que tudo isso requer importante revisão dos aspectos metodológicos, o autor propõe alterações no âmbito das técnicas de coleta dos materiais empíricos. Coerentemente, a sua principal preocupação consiste em se assegurar de que tais alterações colaborem para o pesquisador realizar investigações que levem em conta as múltiplas mobilidades e imobilidades.

A complexidade intrínseca às mobilidades pressupõe que os pesquisadores adotem multimétodos e assim consigam coletar materiais na direção de uma mobilidade que pode apresentar variedade de escalas. A título de ilustração vale exemplificar os sistemas de transporte público e privado; o turismo, a migração e os estudos de fronteira; as comunicações móveis e os softwares apoiados em infraestruturas; o automobilismo e os vários tipos de passageiros (crianças, idosos, trabalhadores, estudantes etc.); as caminhadas, escaladas, ciclismo e outras formas de movimento corporal treinado; estudos do regulamento, governança e estruturas legais pertinentes a todos eles etc. (Sheller, 2011).

A estabilização do que Urry (2007) propõe como novo paradigma das mobilidades requer a adesão da comunidade científica aos pressupostos que ele argumenta. Em linha com o que Sheller (2011, p.9) classificou como guia definitivo, o autor dedica especial atenção ao que nomeia de métodos móveis. Em mais esta oportunidade, o autor é categórico ao afirmar o que pensa nos seguintes termos: "o que eu estabeleço aqui (sic) é que os métodos de pesquisa também necessitam estar 'em movimento', ou seja, para simular de várias maneiras as muitas formas interpendentes e intermitentes de movimentos de pessoas, imagens, informações e objetos" (Urry, 2007 p.39). O esforço de repensar o processo de investigação emerge da necessidade de o pesquisador examinar grande variedade de possibilidades de caráter espacial, social e cultural (D’Andrea et al., 2011). Razão pela qual, valorizam-se cada vez mais as leituras transversais produzidas por grupos de pesquisa formados por acadêmicos oriundos de distintos países e diferentes campos de conhecimento, tais como geografia, turismo, educação, letras, sociologia, arquitetura, design, ciência política, ciência da informação, engenharia, empreendedorismo, entre outras. Assim sendo, é possível observar que as demandas do processo de investigação têm levado os pesquisadores a promover inovações metodológicas que possibilitam ampliar as evidências empíricas pertinentes à pesquisa sobre as (i)mobilidades. Uma das inovações de natureza metodológica está no âmbito instrumental da pesquisa na medida em que se referem às técnicas e as ferramentas de coleta de dados.

Com isso, deseja-se ajustar o processo de investigação às exigências decorrentes das mudanças de natureza espacial, temporal e de movimento. Em especial, as dimensões que tratam das relações efêmeras e afetivas permeadas por relações entre as (i)mobilidades que podem não ser capturadas quando do uso de recursos metodológicos considerados tradicionais (Sheller, 2011).

\section{Os "Métodos Móveis" no Âmbito das Técnicas de Coleta de Dados}

A literatura reúne resultados de pesquisas que retratam a imersão em vários modos de movimento, realização de entrevistas e de grupos focais.

Outros recursos metodológicos contemplam cybersimulações, cyberethnographia, viagem imaginativa, rastreamento de objetos afetivos que capturam memórias existentes sobre determinado lugar, entre outros (Sheller, 2011). No livro intitulado Mobile methods, Büscher et al. (2011) reúnem resultados de pesquisas baseadas na interpretação de conversações estabelecidas entre pessoas, levando em conta a forma como elas se moviam. Uma espécie de etnografia móvel em que o pesquisador considerou os movimentos itinerantes de pessoas e objetos.

Apesar do título (Mobile Methods), os autores não desenvolvem discussões no nível do método propriamente dito, aprofundaram discussões de caráter instrumental, ou seja, no âmbito de técnicas e ferramentas de coleta de dados qualitativos. Observa-se que na literatura sobre o novo paradigma das mobilidades, aquilo que é nomeado de método, na linguagem teórica própria da abordagem qualitativa, não ultrapassa o nível das técnicas de coleta (Fig.1). 


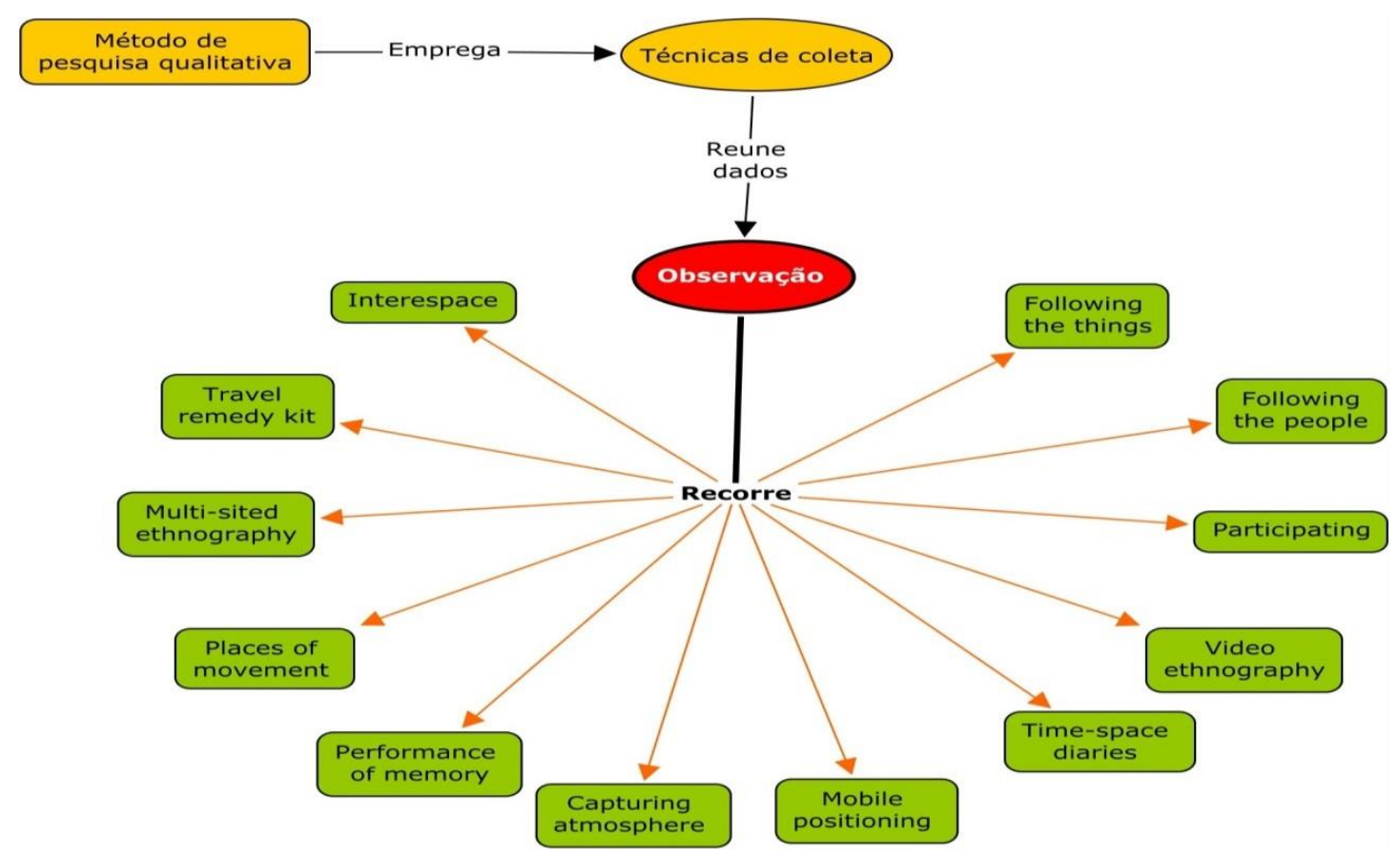

Figura 1: Extensões da Observação

Fonte: Büscher et al. (2011), adaptado pelos autores.

A forma pela qual as técnicas de coleta de dados são descritas remete o leitor às características do método etnográfico uma vez que há ênfase no exercício do olhar (ver) e do escutar (ouvir), ou seja, da observação intensiva. Isso equivale a afirmar que no esforço de se situar no interior do fenômeno observado, por meio da participação efetiva do pesquisador às formas de sociabilidade presentes na realidade investigada, há necessidade de ele se submeter a um deslocamento cultural (Rocha \& Eckert, 2008).

Em se tratando de pesquisas sobre as novas mobilidades, a observação recorre a estratégias específicas de coleta para cada aspecto das mobilidades, revelando-se uma extensão da observação, conforme o conteúdo da Figura 1.

Na sequência, serão destacadas nove técnicas utilizadas nas pesquisas cujos resultados estão descritos no texto de Büscher et al. (2011), levando em conta o foco de observação de cada uma delas.

A seleção dessas técnicas tem como critério principal a sua pertinência para as investigações da mobilidade acadêmica internacional e, por conseguinte, há o esforço de se elencar exemplos de utilização que se enquadrem neste âmbito. Importante destacar que no escopo deste texto, não se trata de uma prescrição quanto ao uso, mas de inserção na discussão acerca dos recursos metodológicos em pesquisas sobre as novas mobilidades.

\section{Observing (observando...)}

O observing também é nomeado following the things. Corresponde a uma técnica de observação que acompanha o movimento dos objetos levando em conta todas as partes onde eles se movimentam. No que concerne à mobilidade acadêmica internacional, há uma série de objetos cujas trajetórias podem ser acompanhadas de forma pormenorizada (isto é, descritas e interpretadas), configurando-se como dados extremamente relevantes para a investigação, tais como: passagens aéreas, passaportes e malas; artigos, livros, dissertações e teses; equipamentos de tecnologia da informação e comunicação, além de outros artefatos ligados ao ensino e à pesquisa. Observa-se que na mobilidade dos objetos, o seu significado cultural podeaumentar na medida em que agrega elementos materiais e simbólicos (Büscher et al., 2011).

Como desdobramento desta técnica de coleta de dados, podem ser empregados modernos recursos de comunicação (a exemplo do rastreamento por GPS ou código de barras, como ocorre na maioria das empresas de correio e logística) a fim de ampliar as possibilidades do mapeamento digital. Ou seja, mede-se o tempo-espaço do movimento de objetos por ruas, prédios e bairros. Recentemente, John Urry 
e equipe organizaram um livro que envolve 13 capítulos cujo conteúdo trata exclusivamente de resultados de pesquisas sobre a mobilidade de objetos (Birtchnell, Savitzky \& Urry, 2015). A obra reflete reconhecido esforço de sistematização e diálogo entre estudos baseados no following the things, por isso mesmo, trata-se da mais completa publicação dedicada à discussão metodológica em investigações que envolvem a mobilidade de objetos.

\section{Participating (andando com...)}

A participating é uma técnica que envolve a participação do pesquisador durante o processo de investigação, ao acompanhar o movimento das pessoas e segui-las de perto ou à espreita. $\mathrm{Na}$ perspectiva da pesquisa das mobilidades, a técnica foi batizada de walking with. A sua utilização visa promover uma aproximação à visão de mundo do observado, que possa revelar seus padrões de atividade, opiniões pessoais e profissionais, apegos emocionais, bem como traços relativos ao seu estilo de vida. Participando do movimento das pessoas, o pesquisador pode, assim, empregar uma série de desdobramentos de técnicas de observação e registros: combinar, por exemplo, a observação com a realização de entrevistas individuais ou em grupo para identificar e/ou construir eventuais categorias de mobilidade acadêmica dos sujeitos pesquisados.

Um bom exemplo de utilização desta técnica é o que Paola Jirón (2011) define como "sombra", em sua pesquisa sobre a mobilidade corpórea na cidade de Santiago do Chile. O procedimento consiste em "se mover com as pessoas [...] de maneira que permita ao investigador ser testemunha e compartilhar as experiências e práticas cotidianas de mobilidade" (Jirón, 2011, p. 41). Desta forma, tão importante como saber o quanto, a que horas ou de que maneira as pessoas viajam, uma investigação baseada no participating necessita examinar as experiências das práticas de mobilidade, isto é, a forma pela qual as pessoas representam, experimentam e imprimem significado às mobilidades, bem como o modo como planejam, incorporam e as constroem, dia após dia (Jirón, 2011, p. 41).

$E$, para isso, faz-se necessário que o investigador esteja junto, participando e experimentando essas mobilidades ao lado do pesquisado, conforme fazem Watts e Lyons (2011), quando investigam as diferentes maneiras com que passageiros materializam e usufruem de viagens de trem na Europa.

\section{Anticipatory following -Video ethnography}

A apropriação desta técnica exige do pesquisador uma antecipação aos movimentos, uma vez que para captar como as pessoas se movimentam e interagem, como em um filme, faz-se necessário posicionar a câmera e ajustar a lente, antes do desenvolvimento das ações. Trata-se de uma técnica especialmente interessante para o acompanhamento das pessoas pesquisadas no decorrer de eventos acadêmicos (tais como seminários, congressos, defesas de teses e dissertações), bem como de quaisquer reuniões e demais encontros entre estudantes, professores e pesquisadores. No âmbito da mobilidade acadêmica internacional, revela-se ainda mais adequado se o investigador tiver acesso, com alguma antecedência, ao cronograma de atividades e demais movimentos a serem realizados pelos pesquisados, possibilitando a realização de registros audiovisuais, com grande riqueza de detalhes, não apenas no interior das instituições a que terá acesso, mas também aos demais locais que constituirão o seu roteiro. Caso haja disponibilidade de recursos, pode-se investir na criação de uma espécie de "circuito de tv", permitindo que outros pesquisadores da equipe tenham acesso em tempo real às práticas de mobilidade dos pesquisados e dos pesquisadores.

Este cenário e muitas outras combinações são sugeridas e discutidas por Büscher et al (2011) no momento em que os autores detalham como a portabilidade de dados de vídeo produzidos por pesquisadores em movimento tem permitido experiências inovadoras de pesquisa no campo das mobilidades, com a construção de verdadeiros bancos de video ethnographies. A disponibilidade de aplicativos de vídeo-chamadas para dispositivos móveis (tais como Skype, Hangouts, Facetime, WhatsApp, Facebook Messenger, Teams e Viber) ou de transmissão de vídeos (como Youtube Live, Facebook Live e o Periscope), tem facilitado o rápido crescimento desse tipo de repositório.

Time-space diaries (diários de tempo/espaço)

No caso desta técnica, os participantes da pesquisa gravam o que estão fazendo no local onde realizam as atividades, sem negligenciar a forma como se movem em cada momento. Estes registros ganham a forma de diários que podem ser textuais, fotográficos, digitais ou a combinação de todos os recursos. A composição de diários possibilita o pesquisador esboçar a forma pela qual os membros de um grupo de pessoas em mobilidade acadêmica 
internacional desenvolvem intermitentes atividades enquanto se deslocam, por exemplo. A vantagem de recursos como correios de voz ou câmeras que registram vídeos reside na possibilidade de os indivíduos não interromperem as atividades que realizam para pensar no conteúdo do que irão registrar, onde estiverem. Para esta técnica, destacam-se aplicativos como Evernote, OneNote, Wunderlist, Google Keep, Apple Notas, além de outros recursos do Office 365.

Esse tipo de registro auxilia na interpretação dos dados qualitativos, pois o conjunto do material registrado reflete um filme da vida diária. Provavelmente seria difícil elaborar uma reflexão sobre estes movimentos, sem registro. Um bom exemplo de aplicação desta técnica é a pesquisa realizada por Alan Latham (2003; 2004). Durante o processo investigatório, o principal material de investigação foi constituído de diários que reuniam fotos e entrevistas. Para compor tais diários, ele solicitou que os participantes da pesquisa (pessoas em mobilidade) escrevessem e fotografassem as suas experiências cotidianas, particularmente, os lugares interessantes e significativos pelos quais passaram. Como bem salienta Jirón (2011), por meio desta técnica é possível minimizar a interferência do investigador a respeito do que e como se registra, atribuindo uma importante parcela da informação coletada aos próprios participantes, que estão no controle do que é coletado (Jirón, 2011, p. 42).

\section{Virtual Mobility (mobilidade virtual)}

Trata-se de um conjunto de técnicas que utiliza mensagens trocadas pela internet como fonte de marcação da mobilidade empreendida por viajantes reais, a fim de caracterizar melhor a experiência das pessoas pesquisadas. Há diversas maneiras através das quais a mobilidade virtual pode ser explorada, entre elas: mensagem de texto instantâneas, websites, grupos de discussão, blogs, mailings, além de outros aplicativos de compartilhamento de imagens, vídeos e informações geolocalizadas. É importante considerar que nem sempre a comunicação e os movimentos no espaço virtual estão facilmente disponíveis ao pesquisador. Portanto, gravar e reproduzir as atividades digitais combinando com interpretação de experiências etnográficas pode ser uma forma de rastrear em diversos espaços, geográficos ou sociais, a ação colaborativa distribuída entre os participantes móveis.
É desse tipo de combinação de recursos técnicos que se valem Haldrup (2011), Morel e Licoppe (2011) e, principalmente, Mondada (2011), ao aliarem técnicas tradicionais de coleta de dados (como entrevistas em profundidade e semiestruturadas) com análise de conteúdo das mensagens trocadas com os participantes da pesquisa, em atividades de mobilidade. No caso da investigação da mobilidade acadêmica internacional, abre-se também a possibilidade de acompanhamento das publicações realizadas em fóruns de sites, plataformas Moocs das universidades, bem como de ferramentas de ensino a distância e LMS (Learning Management System), tais como Moodle, Edmodo, Sakai, Blackboard, Google Classroom, ferramentas da Apple Education e Microsoft Education, além de plataformas como Khan Academy.

\section{Multi-sited ethnography (etnografia multilocalizada)}

A etnografia multilocalizada implica em uma investigação que não está "confinada [... em] um só lugar" (Jirón, 2011, p. 41). Os lugares estão conectados uns aos outros de tal forma que as "relações entre eles" são tão importantes para a investigação quanto as "relações dentro deles" (Hannerz, 2003, p.205 apud Jirón, 2011, p.41). Diferentemente dos "meros estudos comparativos de localidades", neste caso, o mais relevante é compreender as vinculações que permitem as conexões entre os lugares, ou, como bem definiu Marcus (1995, p.105 apud Büscher et al., 2011) suas "correntes, caminhos, linhas, conjunções ou justaposições".

No âmbito da mobilidade acadêmica internacional, a etnografia multilocalizada permite explorar, por exemplo, através da descrição densa e multifacetada, as rotinas diárias das pessoas nas localidades que frequentam e ao longo do seu deslocamento, tendo como foco o significado que atribuem à sua experiência e as motivações de estarem em cada lugar e estabelecer conexões entre eles.

Um bom exemplo desta técnica seria o estudo das práticas de mobilidade de estudantes, professores e/ou pesquisadores vinculados a mais de uma instituição, tendo como foco não apenas as viagens que realizam entre uma e outra, mas também a lógica de vinculação e as relações que envolvem os distintos tipos de mobilidade existentes entre essas duas instituições. 
Mobile positioning methods (métodos de posicionamento móvel)

Os celulares são amplamente utilizados como ferramenta de coleta de dados em virtude de sua capacidade de capturar posições dos indivíduos na cena espacial. Isso pode se dar ativamente, olhando a posição em tempo real, ou passivamente, trabalhando com banco de dados histórico. O registro desses dados pode ser facilitado por meio das ferramentas de "check-in" existentes nos aplicativos e redes sociais, tal como acontece, por exemplo, com o Facebook, Instagram, Maps (Google e Apple), Yelp, Foursquare, Google Plus, Swarm, Uber, que possuem um botão específico para que as pessoas compartilhem (de forma pública ou privada) a sua localização, bem como as suas principais práticas de mobilidade.

Mondada (2011) utiliza esta técnica de forma inusitada ao coletar e analisar mensagens trocadas por pessoas em mobilidade que, em algum momento, seus veículos de transporte precisam de assistência mecânica, antes de seguirem viagem. Não obstante, a tecnologia da informação já permite, $a$ priori, que a geolocalização dos indivíduos seja registrada de forma automática, sem qualquer ação necessária por parte do pesquisado. Este recurso oferece oportunidades para estudos inéditos de comportamento espacial na vida cotidiana e é discutido com detalhes em recente livro organizado por Jordan Frith, também pesquisador do CeMoRe: Smartphones as Locative Media (Frith, 2014). Aliada à geolocalização há também a possibilidade de se realizar surveys por meio do dispositivo móvel (até mesmo de forma automática, em que distintos tipos de questionários são disponibilizados no smartphone conforme o respondente se movimenta), ampliando sobremaneira as possibilidades de preenchimento do instrumento de coleta de dados.

Performance of memory (desempenho da memória)

$O$ resgate da memória pode envolver pessoas, lugares e relações. Para recuperá-la, podem-se empregar técnicas de investigação qualitativa debruçando-se sobre documentos, fotografias, cartas, imagens, livros, dispositivos/equipamentos, souvenirs e outros objetos usados especialmente por estudantes, professores e/ou pesquisadores, no interior das instituições em que atuam ou mesmo em seu ambiente doméstico.
Trata-se de uma técnica que não se limita à pesquisa documental, mas abrange também a utilização dessas imagens e demais objetos com o intuito de "reascender a memória" dos pesquisados sobre as suas experiências e aspectos relevantes ligados à mobilidade acadêmica que vivenciaram. A utilização do histórico nas redes sociais pode ser um importante balizador e disparador dessas memórias, uma vez que se configuram como verdadeiros repositórios de mensagens, imagens e registros que, intencionalmente ou não, ficam "guardados na nuvem" e podem ser recuperados, mesmo depois de extenso intervalo de tempo.

Os melhores exemplos desse tipo de ferramenta são o Instagram, SnapChat, Pinterest, Google Plus e Facebook, que possuem elevada capacidade de armazenamento. Um exemplo recente do potencial desse tipo de ferramenta é o recurso criado pelo Google (em diversos aplicativos, como Maps, Fotos, Plus) capaz de oferecer acesso a fotos e demais mensagens existentes nos dispositivos para criar automaticamente (por meio de algoritmos) "histórias ligadas à mobilidade" das pessoas. O serviço "oferece gratuitamente" ao usuário uma "narrativa" (em formato de foto ou vídeo-montagem) com base nas imagens, vídeos e áudios registrados pelo smartphone, tablet e/ou smartwatch, nos deslocamentos realizados e nos demais registros existentes nesses dispositivos. Essa "história" pode, por sua vez, ser editada pelo usuário e ficar registrada na memória da rede social para utilização futura.

Places of movement (locais de movimento)

Lugares reais não são necessariamente fixos, podem ser móveis dentro de uma complexa rede de agentes humanos e não humanos. Os lugares são dinâmicos, movem-se. Por isso, podem não ser fixados a determinada localização. A realidade virtual e outros recursos disponibilizad os com a emergência da "web 2.0" permitem o acesso a experiências de mobilidade sem a necessidade de deslocamento corpóreo. Isso ocorre, por exemplo, nos casos de experiência de "visitas" ou "deslocamentos" por meio de ferramentas como o Google Maps - Street View e museus virtuais, que oferecem vistas panorâmicas de 360 , permitindo que as pessoas "se movimentem" por esses espaços. Há também os casos de compartilhamento de vídeos e imagens em tempo real (pelos indivíduos in loco) que permitem as pessoas de todo o planeta o acompanhamento de um acontecimento ou evento (Büscher et al., 2011). 
Trata-se de um recurso já utilizado por agências de notícias e outros meios de comunicação que necessitam acessar a determinados locais, antes mesmo do deslocamento corpóreo de suas equipes.

No âmbito da mobilidade acadêmica internacional, não são poucas as universidades e centros de pesquisa que disponibilizam pela internet "live cams" vários de seus espaços de interação e movimentação de pessoas. Muitas delas podem ser acompanhadas por sites como o MassWebcams (http://masswebcams.com/) e EarthCam (http://www.earthcam.com/). Os obstáculos que mais dificultam esse tipo de mobilidade têm sido alvo das empresas de tecnologia da informação, como é o caso da dificuldade da compreensão de uma língua estrangeira. Já há disponíveis (na versão de teste), por exemplo, serviços gratuitos como o do Skype Translator, que permitem a tradução simultânea em tempo real de vídeo-chamadas ou videoconferências realizadas pela ferramenta, o que, ao menos em tese, permitiriam outras práticas de mobilidade que até hoje eram inacessíveis a quem não dominasse outros idiomas.

Sublinha-se que as técnicas de coleta de dados antes descritas envolvem a exploração isolada ou combinada de múltiplos recursos digitais (equipamentos, componentes, wearables, GPS, softwares, websites, blogs, mailings, network etc.), reforçando o fato de que as mídias estão presentes nos processos de reformulação das paisagens urbanas. Dois conceitos formulados por Appadurai (1990) - technoscapes e mediascapes - colaboram para a reflexão em curso na medida em que explicam a influência do uso intenso e ampliado das tecnologias sobreas alterações que se processam na vida cotidiana das pessoas. O autor utiliza estes conceitos na expectativa de colaborar para explicitar as dimensões que se relacionam em um fluxo cultural global. Enquanto os technoscapes contemplam configurações globais a partir do fluxo de tecnologias, tanto mecânicas quanto informativas, que se movem em alta velocidade através de vários tipos de fronteiras, antes impenetráveis; os midiascapes são comparáveis à distribuição em ampla escala dos recursos eletrônicos que visam produzir e disseminar dados e informações (jornais, revistas, emissoras de televisão, estúdios de cinema etc.). Assim sendo, os mediascapes colaboram para o fornecimento de complexos repertórios de imagens e narrativas que despertam interesse em várias partes do mundo (Appadurai, 1990). Por isso mesmo, os referidos conceitos podem inspirar a emergência de múltiplas possibilidades de pesquisas.

\section{CONSIDERAÇÕES FINAIS}

O conjunto de técnicas antes descritas não deixa de ser importante fonte de inspiração para os pesquisadores que investigam temas subordinados às novas mobilidades. Renovações no âmbito dos métodos científicos são sempre bem-vindas porque no ambiente acadêmico há consciência de que qualquer recurso metodológico apresenta limitações que merecem ser enfrentadas.

O uso recorrente de recursos tecnológicos no campo, tais como registros em câmera fotográfica, laptops, smartphones, smartwatchs, drones, áudio, vídeo, GPS etc. suscita uma primeira preocupação de caráter ético. Essa preocupação se justifica na medida em que algumas das técnicas, antes descritas, preveem registros nem sempre autorizados porque nem sempre as pessoas são informadas de que estão sendo observadas. Essa questão merece ser enfrentada no âmbito dos comitês de ética das universidades, por exemplo, e mereceu especial atenção no livro recentemente publicado pelo CeMoRe, sobre o uso de smartphones como dispositivos de localização. Nesta publicação, Jordan Frith (2015) dedica um capítulo à discussão sobre questões ligadas à privacidade e ao uso de dispositivos móveis (The negotiation of locational privacy). Na oportunidade, ele alerta para o fato de que muitos países carecem de legislação específica que trate desta questão. O Brasil é um caso interessante nesse sentido, uma vez que a modernização de suas leis não tem acompanhado o rápido crescimento de acesso de sua população à internet, que ocorre principalmente por meio de smartphones e tablets. Esse fenômeno é analisado em detalhes por Adriana de Souza e Silva, professora e pesquisadora da Universidade da Carolina do Norte (Estados Unidos), e caracterizado como a emergência de uma "cultura móvel" no país - Mobilefest and the emergence of a mobile culture in Brazil (Duarte \& Silva, 2014). A descrição de algumas técnicas também gera a desconfiança de que no âmbito dos mobile methods haja excesso de atenção nos recursos tecnológicos explorados. Isso é particularmente intrigante quando se tratam de pesquisas inspiradas pelo método etnográfico na medida em que pode ocasionar indesejável distanciamento entre o etnógrafo e os atores sociais implicados. Afinal, é a experiência imediata do movimento que o 
pesquisador procura resgatar em primeiro plano. $\mathrm{O}$ compromisso com a investigação de populações dispersas apresenta óbvias dificuldades operacionais que restringem os próprios padrões etnográficos de movimentos durante a coleta de dados no campo (D'Andrea et al., 2011).

A depender do escopo da investigação em curso, torna-se inviável não se valer do auxílio das tecnologias. Portanto, há de se ponderar acerca da pertinência da adoção de novas técnicas de pesquisa de campo, uma vez que, de acordo com o método utilizado, os resultados podem ser questionáveis. A inserção das tecnologias na pesquisa acadêmica estimula a formulação de interrogações sobre a própria atividade investigativa, revelando trilhas para novas perguntas e ampliação o foco do pesquisador (Belei, 2008). É fato que a evolução dos meios de transporte e de comunicação tornou possível a conexão com qualquer parte do mundo, fazendo com que as transformações na velocidade e no alcance desses meios engendrassem impactos sociais significativos. No entanto, o uso da tecnologia apresenta limites na medida em que ao mesmo tempo em que ela viabiliza a interação de pessoas instaladas nos mais diversos lugares do mundo, ela compromete os relacionamentos locais; ao mesmo tempo em que é possível estabelecer contato com um número maior de pessoas, menos tempo é direcionado a cada uma (Adams, 2011), favorecendo a quantidade em detrimento da qualidade/intensidade dos relacionamentos, favorecendo a frequência em detrimento da profundidade. Isso preocupa quando a literatura (Cresswell, 2006) chama atenção para o fato de a produção da mobilidade assumir um caráter bifacial na medida em que combina dimensões corporal e social e isso enfraquece os resultados das investigações que se limitam a gerar explicações sobre os deslocamentos em si. Ao buscar estabelecer uma ponte entre os conceitos envolvidos nas novas mobilidades e os recursos metodológicos implicados na pesquisa acadêmica, há de se levar em consideração que flui sob esta construção, tanto indivíduos quanto grupos sociologicamente regidos por ideologias produzidas; quiçá impostas por sua

\section{REFERÊNCIAS}

Adams, J. Hypermobility. (2000). Prospect, Londres, mars. Recuperado em fevereiro, 2018. Versão em francês disponível em: www.worldcarfree.net/.../Hypermobility.rtf.. classe social, cujas bases podem estar centradas no Estado, na religião, nas instituições de educação formal e no ambiente de trabalho. Compete lembrar que as pessoas tendem a reproduzir o que aprend em nesses ambientes. Desta forma, não só se apropriam desta aprendizagem, mas compartilham com o meio social em que se inserem, estabelecendo o chamado senso comum (Duarte et al, 2009). Contudo, ainda que as questões institucionais, profissionais e pessoais possam definir os contornos do projeto de investigação, a viabilidade das práticas de pesquisa torna-se muitas vezes, a sua própria legitimidade. 0 próprio percurso da pesquisa é permanentemente negociado em função das limitações, expectativas e oportunidades que constituem o campo real da investigação (D’Andrea et al., 2011).

A inquietação com a singularidade das novas mobilidades como um fenômeno sui generis requer um aporte metodológico e conceitual particular. As explicações holísticas fenomenológicas e etnográficas móveis contribuem para desenvolvimento e aprimoramento de técnicas e estratégias de investigações. Visto por este ângulo, pode-se questionar até que ponto as exigências intrísecas à investigação de fenômenos subordinados às novas mobilidades serão capazes de promover uma revolução metodológica?

Para D'Andrea et al. (2011), não se trata de uma revolução, mas de um processo contingente de ajustes, tanto no âmbito do método, quanto no nível dos conceitos e dos procedimentos uma vez que o pesquisador não pode desconsiderar as especificidades e exigências dos projetos de pesquisa. As inovações metodológicas e conceituais recorrentemente derivam da formação de pontes transdisciplinares como condição necessária para o êxito de investigações que possam gerar novas linguagens e ideias que facilitem a compreensão de aspectos emergentes de um mundo (im)móvel. Ainda assim, cabe alertar para uma possível redução metodológica, considerando que os métodos devem ser definidos em consonância com a teórica específica e compromissos epistemológicos do pesquisador (D'Andrea et al., 2011).

(2011). The social consequences of hypermobility. RSA Lecture. Recuperado em fevereiro de 2018. Disponivel em: http://johnadams.co.uk/wpcontent/uploads/2006/hypermobilityforRSA.pdf. 
Almeida, A. M. F. et al. (Org.). (2004). Circulação internacional e formação intelectual das elites brasileiras. Campinas: Editora Unicamp.

Amar. G. (2016). .Homo mobilis - une civilization du mouvement: de la vitesse à la reliance. Limoges/Fr: Fyp Édotion.

(2011). Homo mobilis - la nueva era de la movilidad. Buenos Aires: La Crujia Ediciones.

Appadurai, A. (1990) Disjuncture and difference in the global cultural economy, Theory Culture Society, 7 (2), 295-310. Disponivel em: http://tcs.sagepub.com (consulta em fev.2018)

Augé, M. (2009). Pour une anthropologie de la mobilité. Paris: Payot \& Rivages.

Ballatori, M. (2007). L'experience de mobilité des étudiants ERASMUS: les usages inégalitaires d'un programme d'échange - une comparaison Anglaterre, Relatório de Tese. Université AixMarseille 1 / Università Degli Studi di Torino, France, Italie.

(2010). Erasmus et la mobilité des jeunes Européens. Paris: PUF.

Bauman, Z. (2017). Estranhos à nossa porta. Rio de Janeiro: Zahar.

(2008). Vida para consumo: a transformação das pessoas em mercadoria. Rio de Janeiro: Zahar.

(2005). Vidas desperdiçadas. Rio de Janeiro: Jorge Zahar.

(1999). Globalização - as consequências humanas. Rio de Janeiro: Jorge Zahar.

Belei, R. A., Gimeniz-Paschoal. S. R, Nascimento,E. N, Matsumoto, P. H. V. R. (2008). O uso de entrevista, observação e videogravação em pesquisa qualitativa. Cadernos de Educação, FaE/PPGE/UFPel. Recuperado em fevereiro, $2018 . \quad$ Disponível em: http://www.ufpel.edu.br/fae/caduc/downloads/n30 111.pdf

Billaud, S. (2007). Mises au point sur les mobilités européenes. In: Dervin, F.; Suomela-Salmi, E. (Org.) Mobilité académique - perspectives croisées. Turku: Université de Turku/Département d'Études Françaises.

Birtchnell, T., Savitzky, S. \& Urry. (2015). Cargomobilities: moving materials in a global age. Routledge, Changing Mobilities.
Bourdin, A. (2007). Mobilité et écologie urbaine. Paris: Descartes \& Cie.

Büscher M. \& Urry J. (2009). Mobile Methods and the Empirical. European Journal of Social Theory. Recuperado em março, 2018. Disponível em: http://est.sagepub.com/content/12/1/99.

Büscher M., Urry J. \& Witchger K. (2011). Mobile methods. London and New York: Routledge.

Cresswell, T. (2010). Mobilities I: Catching up. Royal Holloway, University of London, UK, Progress report. SAGE. Recuperado em março, 2015. Disponível em: http://phg.sagepub.com/content/35/4/550.

Cresswell, T. (2006). On the move: mobility in the modern western world. New York: Routledge.

D’Andrea, A., Ciolfi, L. \& Gray, B. (2011). Methodological Challenges and Innovations. IN: Mobilities Research. 6 (2). Recuperado em março, 2018. Disponível em: http://www.tandfonline.com/doi/pdf/10.1080/1745 0101.2011 .552769$.

Dervin, F. \& Byram, M. (dir.). (2008). Échanges et mobilités académiques: quel bilan? Paris: L'Harmattan.

\&Ljalikova, A. (dir.). (2008). Regards surles mondes hypermobiles: mythes et réalités. Paris: L'Harmattan.

\& Suomela-Salmi, E. (Org.) (2007). Mobilité académique - perspectives croisées. Turku: Université de Turku/Département d’Études Françaises.

Duarte, F. \& Souza E S. A. (2014). "Arte.mov, Mobilefest and the emergence of a mobile culture in Brazil. In: G. Goggin, \& Hjorth, L. (Eds.). The Routledge companion to mobile media. New York: Routledge, pp. 206-215.

Duarte, S., Mamede, M. V. \& Andrade, S. M. O. (2009). Opções teórico-metodológicas em pesquisas qualitativas: representações sociais e discurso do sujeito coletivo. Saúde Soc., 18 (4). Recuperado em janeiro, 2018. Disponível em: http://www.scielo.br/scielo.php?script=sci arttext\& pid=S0104-12902009000400006\&lng=en\&nrm=iso.

Duarte R. (2002). Pesquisa Qualitativa: reflexões sobre o trabalho de campo. Cadernos de Pesquisa, 115, p. 139-154. Recuperado em abril, 2018. Disponível em www.scielo.br/pdf/cp/n115/a05n115.pdf 
Ennaffa, R. \& Paivandi, S. (2018). Les étudiants étrangers en France. La Documentation Française.

Erlich, V. (2012). Les mobilités étudiants. Paris : La Documentation Française.

Frith, J. (2014). Smartphones as locative media. New York: Routledge.

Garneau. S. (2006). Les mobilités internationales à l'ère de la globalisation. Une comparaison sociologique des carrières spatiales et des socialisations professionnelles d'étudiants français et québécois. Relatório de Tese. Université LumièreLyon.

Jirón, P. (2011). On becoming "la sombra/the shadow". In: Büscher M, Urry J \& Witchger K. Mobile methods. London and New York: Routledge.

Haldrup, M. (2011). "Chroreographies of leisure mobilities". In: Büscher M, Urry J \& Witchger $\mathrm{K}$. Mobile methods. London and New York: Routledge.

Hannam, K., Sheller, M \& Urry, J. (2006). Editorial: Mobilities, Immobilities and Moorings. Mobilities. 1 (1), 1-22. Recuperado em março, 2018. Disponível em: http://www.lancs.ac.uk/fass/projects/medmobilities/d ocs/Editorial-Mobilities.pdf.

Hannerz, U. (2003). "Being there... and there... and there! Reflections on multisite ethnohraphy". Ethnography, 4 (2), 201-16.

Hayles, N. K. (1999). How we became post human: virtual bodies in cybernetics, literature, and informatics. Chicago: University of Chicago Press.

Latham, A. (2003). "Research, performance, and doing human geography: some reflections on the diaryphotograph, diary interview method" IN: Environment and Planning A, 35, pp. 1993-2017.

(2004). "Researching and writing everyday accounts of the city: an introduction to the diary-photo diary-interview method", IN: C Knowles and $\mathrm{P}$, Sweetman (eds) Picturing the visual landscape: visual methods and the sociological imagination. Routledge, London, pp $1699-1724$.

Lévy, J. (2008). L'invention du monde. Une géographie de la mondialisation, Paris: Presses de Sciences Po.

Machart, R. \& Dervin, F. (sous la direction). (2014). Les nouveaux enjeux des mobilités et migrations académiques. Paris : L'Harmattan.
Marcus, G. (1995). "Ethnography in/of the world system: the emergence of multi-sited ethnography" IN: Annual review of anthropology, 24, 95-117.

Mondada, L. (2011). "Reassembling fragmented geographies". In: Büscher M; Urry J; Witchger K. Mobile methods. London and New York: Routledge.

Morel J. \& Licoppe, C. (2011). "Studying mobile video telephony". In: Büscher M; Urry J; Witchger K. Mobile methods. London and New York: Routledge.

Murphy-Lejeune, E. (2003). L'étudiant européen voyageur, un nouvel étranger. Paris: Didier.

Ocde. (2014). Education at a glance 2014. Paris: Ocde.

Ouziel, J. (2004). La valorisation du capital humain. La Revue des Sciences de Gestion, Direction et Gestion, 210.

Pinto, C. (2013). Mobilité social et mobilité internationale d'étudiants étrangers : trajectoires de jeunes professionnels chiliens e colombiens à Paris, New York et Boston. Relatório de Tese. Université Paris-Est.

Rocha, A. L. C. \& Eckert, C. (2008). Etnografia: saberes e práticas. In: Ciências Humanas: pesquisa e método, Céli Regina Jardim Pinto e César Augusto Barcellos Guazzelli (Org.). Porto Alegre: Editora da Universidade.

Santos, B. S. (Org.). (2003). Reconhecer para libertar: os caminhos do cosmopolitismo multicultural. Rio de Janeiro: Civilização Brasileira.

Sheller M. (2011). Mobility. Sociopedia.isa, Drexel University. Recuperado em março, 2018. Disponível em: http://www.sagepub.net/isa/resources/pdf/Mobility.pdf.

Terrier, E. (2010). Mobilites et experiences territoriales des etudiants internationaux en Bretagne. Relatório de Tese. Université de Rennes 2.

Unesco. (2012). Recueil des donneés mondiales sur l'éducation: statistiques comparées sur l'éducation dans le monde, Montreal: Unesco.

Urry, J. (2005). Les systèmes de la mobilité. Cahiers internationaux de sociologie, n.118. (2007). Mobilities. Cambridge: Polity Press.

Watts, L. \& Lyons, G. (2011). Travel remedy kit: interventions into train lines and passenger times. In: Büscher M, Urry J \& Witchger K. Mobile methods. London and New York: Routledge. 
Winckler, S. (2001). A condição jurídica atual dos imigrantes no cenário internacional à luz do pensamento da Hannah Arendt. In: AGUIAR, O. A. (et al). Origens do Totalitarismo 50 anos depois. Rio de Janeiro: Relume Dumará; Fortaleza: Secretaria de Cultura de Desporto.

\section{SOBRE OS AUTORES}

- Manolita Correia Lima - Escola Superior de Propagada e Marketing - ESPM, São Paulo, (Brasil). E-mail: mclima@espm.br Orcid id: https://orcid.org/0000-0001-6852-2997

- Claudia Cristiane dos Santos Silva - Escola Superior de Propagada e Marketing - ESPM, São Paulo, (Brasil). E-mail: claudia@espm.br Orcid id: https://orcid.org/0000-0003-4651-5301

- Danilo Martins Torini - Escola Superior de Propaganda e Marketing - ESPM, São Paulo, SP (Brasil). Email: danilotorini@gmail.com Orcid id: https://orcid.org/0000-0001-6163-3192

\section{Mobile Methods in the Context of the New Mobility Paradigm}

Manolita Correia Lima, Claudia Cristiane dos Santos Silva, Danilo Martins Torini Escola Superior de Propaganda e Marketing - ESPM, São Paulo, Brasil

\section{DETALHES DO ARTIGO}

\section{Article history:}

Guest Article

Available online April: 01th 2019

Double Blind Review System

\section{Scientific Editor}

Ilan Avrichir

\section{Keywords}

New Mobility

Mobile Methods

International Academic Mobility

\section{RESUMO}

This article will reflect on the proposed renewal of the methodological resources required by the investigation of themes related to "new mobilities". The literature dedicated to understanding the impacts of these mobilities has argued the need to rethink the methodological resources explored and the importance of formulating methodological alternatives to those that are repeatedly explored. Taking into account that the authors of this text are part of a research group dedicated to the investigation of international academic mobility and that the practice of research points to the limitations of methodological resources traditionally explored, they have decided to consolidate the contributions that the international literature has offered in this field and to socialize with stakeholders. The text will be divided into two parts: while the first explores the paradigm of new mobilities formulated by researchers at the Center for Mobilities Research (Lancaster University), the second discusses what field scholars have been calling "mobile methods". Taking into account that the possibilities of using mobile methods are as broad and diversified as the field opened by the "new mobilities paradigm", the text will be illustrated with examples drawn from research on international academic mobility, focusing on the discussion of techniques that make intensive use of information technology and mobile devices, without disregarding ethical issues.

(C) 2018 Internext | ESPM. Todos os direitos reservados!

\section{Para citar este artigo:}

Lima, M., Silva, C., \& Torini, D. (2019). Métodos Móveis no Contexto do Paradigma das Novas Mobilidades. Revista Eletrônica de Negócios Internacionais, 14(2), 145-160. doi:http://dx.doi.org/10.18568/internext.v14i2.533 